\title{
Real-Time Management of Groundwater Resources Based on Wireless Sensors Networks
}

\author{
Qingguo Zhou ${ }^{1, *}$, Chong Chen ${ }^{2}$, Gaofeng Zhang ${ }^{1}$, Huaming Chen ${ }^{3}$, Dan Chen ${ }^{1}$, Yingnan Yan ${ }^{1}$, \\ Jun Shen ${ }^{3, *}$ (i) and Rui Zhou ${ }^{1}$ \\ 1 School of Information Science and Engineering, Lanzhou University, Lanzhou 730000, China; \\ zhanggaof@lzu.edu.cn (G.Z.); chend13@lzu.edu.cn (D.C.); yanyn15@lzu.edu.cn (Y.Y.); zr@lzu.edu.cn (R.Z.) \\ 2 College of Geophysics and Information Engineering, China University of Petroleum, Beijing 102249 China; \\ chenchong87@gmail.com \\ 3 School of Computing and Information Technology, University of Wollongong, Wollongong, NSW 2522, \\ Australia; hc007@uowmail.edu.au \\ * Correspondence: zhouqg@lzu.edu.cn (Q.Z.); jshen@uow.edu.au (J.S.)
}

Received: 20 December 2017; Accepted: 11 January 2018; Published: 13 January 2018

\begin{abstract}
Groundwater plays a vital role in the arid inland river basins, in which the groundwater management is critical to the sustainable development of area economy and ecology. Traditional sustainable management approaches are to analyze different scenarios subject to assumptions or to construct simulation-optimization models to obtain optimal strategy. However, groundwater system is time-varying due to exogenous inputs. In this sense, the groundwater management based on static data is relatively outdated. As part of the Heihe River Basin (HRB), which is a typical arid river basin in Northwestern China, the Daman irrigation district was selected as the study area in this paper. First, a simulation-optimization model was constructed to optimize the pumping rates of the study area according to the groundwater level constraints. Three different groundwater level constraints were assigned to explore sustainable strategies for groundwater resources. The results indicated that the simulation-optimization model was capable of identifying the optimal pumping yields and satisfy the given constraints. Second, the simulation-optimization model was integrated with wireless sensors network (WSN) technology to provide real-time features for the management. The results showed time-varying feature for the groundwater management, which was capable of updating observations, constraints, and decision variables in real time. Furthermore, a web-based platform was developed to facilitate the decision-making process. This study combined simulation and optimization model with WSN techniques and meanwhile attempted to real-time monitor and manage the scarce groundwater resource, which could be used to support the decision-making related to sustainable management.
\end{abstract}

Keywords: groundwater management; real-time; simulation; optimization; sustainable

\section{Introduction}

Freshwater is a precious resource. It is essential for agriculture, domestic usage, industry, and environment. Rapid economic growth, population growth, urbanization, and the continuous expansion of human development have aggravated water scarcity in many basins. Owing to several unique features (e.g., widespread and continuous availability, low development cost, and drought reliability), groundwater has become one of the most important sources of water supplies among the available water resources throughout the world in the last few decades. The importance of groundwater resources increases with the continuous growth in the world's population, which is expected to reach 11.2 billion in 2100 [1]. Therefore, it is very important to sustainably manage groundwater resources to satisfy the increasing demand. However, because of a lack of policy making and supervision measures 
for utilization, the over-exploitation of groundwater in many areas has been extensive, altering flow regimes and thereby becoming a threat to socio-economic development and ecological health [2]. The middle reaches of Heihe River Basin (HRB), which is located in the arid regions of Northwestern China, have faced serious water problems [3]. In the last 30 years, the groundwater level has declined along with the dramatic increase of agricultural pumping wells (from 3199 in 1985 to 6275 in 2005). In the Daman irrigation district, the groundwater level has dropped $20 \mathrm{~m}$ due to unconstrained groundwater exploitation. A number of studies have tried to tackle the groundwater resources management problems using scenario analysis $[4,5]$. However, selecting the optimal operational procedure or policy is extremely difficult because of the complexity of groundwater systems and relatively limited onsite studies. To address this difficulty, it is suggested that groundwater simulation models be linked with optimization techniques to obtain the best (or optimal) management strategy from many possible strategies [6]. These approaches are all based on static data that cannot reflect real-time situations. Therefore, decisions, which are made based on these approaches, are always obsolete to some extent. On the other hand, among traditional sampling techniques related to groundwater monitoring, the most common method is grab sampling, which can be conducted on-site using handheld instruments. Grab sampling is subject to several disadvantages. The process is labor-intensive and costly, and the sampling interval is quite large, which leads to sparse datasets.

With the rapid development of Information and Communications Technology (ICT), Wireless Sensors Network (WSN) techniques have gained worldwide attention in recent years. The WSN was already recognized as part of the Earth Observing System (EOS) by most researchers. Many famous institutions in Geo-Information Science (United States Geological Survey (USGS), National Research Council (NRC), National Geo-Spatial-Intelligence Agency (NGA), etc.) have considered WSN as an extension and an important part of EOS, the International Earth Observing System, and the Global Earth Observation System of Systems. In the field of hydrology, WSN is also an important source of observation data. In China, the research and development of major projects and frontier fields in the National Plan for Medium- and Long-term Science and Technology Development (2006-2020) have emphasized WSN as an important direction. The emerging technology of WSN can be used to mitigate the aforementioned problems due to its integrity and wireless network of sensing devices. WSN requires little maintenance once they are deployed. The sampling interval can be from minutes to days. Therefore, the real-time management of groundwater system should be designed in concert with a WSN.

In this paper, we developed a real-time groundwater management system for the Daman irrigation district in the middle reaches of the HRB. The WSN techniques were used in the system in order to provide real-time data. We also optimized a proposed highly efficient and reliable method to calculate the pumping yields of groundwater, subject to the constraints of the groundwater level. A numerical model was constructed to provide objective function evaluations. A larger boundary was selected to provide the boundary conditions for the Daman irrigation district. The contributions of this paper include

1. developing a simulation-optimization model to analyze the groundwater level data;

2. designing and implementing an architecture of a real-time groundwater management system to provide real-time support for decision-making.

This work is inter-disciplinary in nature. Different expertise from computer science and environmental engineering were combined. We anticipate that this paper will contribute to research on real-time sustainable management of groundwater resources. Findings on intelligent techniques for sensor data collection can be found in [7].

\section{Related Work}

A number of studies have tried to tackle the sustainable management problems of groundwater resources using monitor systems and model simulations [8-10]. Groundwater flow and land 
deformation was integrated in an anisotropic aquifer system. The model was applied to conduct pumping recovery tests under various conditions in order to design groundwater pumping projects for Shanghai, China [11]. Carmen et al. proposed a hydro-economic model to balance the trade-off between sustainable management of groundwater resources and the cost of overexploited aquifers in the Segura basin, Southeast Spain [12]. Huo et al. integrated a soil and water assessment tool (SWAT) for simulating surface water and MODFLOW for simulating groundwater in order to explore the discharge from rivers under future predictions [4]. A few optimization techniques have been used for irrigation management [6,13-16]. Sadeghi-Tabas et al. proposed an attempt to link MODFLOW to a multi-algorithm genetically adaptive search method (AMALGAM) to optimize pumping rates of a groundwater system in Iran [17]. A surrogate-based approach was developed based on integrated surface water-groundwater modeling to optimize the percentages of surface water and groundwater in irrigation water in order to obtain a better balance between groundwater storage in the middle reaches of HRB and the environmental flow in the lower reaches [18]. Hamid R. Safavi and Mehrdad Falsafioun combined a genetic algorithm optimization model with scenario analysis to develop an optimal plan for the conjunctive use of surface water and groundwater resources in Zayandehrud Basin, Iran [19]. However, these researches were based on static data, which were relatively obsolete.

As recent technology advancements have been made with WSN, environmental monitoring is becoming feasible. Environmental sensor networks provide a powerful combination of distributed sensing capacity, real-time data visualization and analysis, and integration with adjacent networks and remote sensing data streams. Rundel et al. reviewed environmental sensor networks in ecological research [20]. Lin et al. examined the relationship between home occupant behavior and indoor air quality by collecting both sensor-based behavior data and chemical indoor air quality measurements in smart home environments [21]. Jiang et al. [22] developed a water environmental monitoring system based on WSN. The system auto-monitored the water temperature and $\mathrm{pH}$ value of an artificial lake. This study made use of WSN to monitor the environment in real time. WSN have been integrated with groundwater contamination transport models in a realistic simulative environment [23]. This study focused on the contaminant transport and suggested that contaminant transport models could benefit from WSN techniques as WSN become more sophisticated. In this study, advances in WSN, groundwater simulations, and optimizations were integrated to sustainably manage groundwater resources in real time.

\section{Materials and Methods}

\subsection{Study Area}

The Daman irrigation district, located in the upper part of the middle reaches of HRB, was selected to examine the proposed groundwater management system. Located in the northwest of China (Figure 1), the HRB is dominated by very limited $(69-216 \mathrm{~mm})$ precipitation but strong evaporation (1453-2351 mm). The Heihe River flows into the middle reaches through Yingluo Gorge hydrologic station located in the southeast area of the basin and flows out through the Zhengyi Gorge hydrologic station located in the northwest area of the basin. About 788 pumping wells have been constructed in the Daman irrigation district since the 1980s [24]. The groundwater level declined $20 \mathrm{~m}$ in the past 20 years due to the overexploitation of groundwater. An observation well at $38.8 \mathrm{~N}$ and 100.4 E was constructed in the Daman irrigation district, and time series data of the groundwater level has been obtained since the 1980s. In this work, we primarily focused on utilizing the data of the Daman irrigation district, and the time period was set to one year. All well data were collected and preprocessed for the structured groundwater study via the sensor network $[7,25,26]$. Meanwhile, the feedback and executors, operating in the real fields, were also deployed by the remote sensor network. We will detail the backend system design and development in the following sections. 


\subsection{System Design}

The scheme of the real-time groundwater management system is illustrated in Figure 2. Recent achievements in hydrology tended to benefit from the development and application of sensor technology, wireless communication, and information infrastructure. Six groundwater probes (HOBO water level Logger U20-001-01 and U20-001-01-Ti) were installed in the middle reaches of the Heihe River Basin (Figure 1) with the capability of recording the pressure of the groundwater (which could be used to obtain the groundwater level) and the temperature of the groundwater. One of the probes was deployed in the Daman borehole. All sensors were connected to a data logger, and the data recording interval was setting to one hour. The groundwater depth could derive from the pressure of the groundwater. Together with the depth of $\mathrm{HOBO}$ and the elevation from differential global positioning system (GPS), the groundwater level was calculated. The observed data was relayed to the database via the General Packet Radio Service (GPRS). The groundwater level was used by the simulation-optimization model to generate an optimal water usage scheme in order to assist in decision-making. The decisions would have positive or negative effects on the groundwater resources, effects that could be later observed by the probes. As building this real-time management system of groundwater was our first attempt, the time interval was set to one year. The observed data by HOBO was averaged to the system time interval.

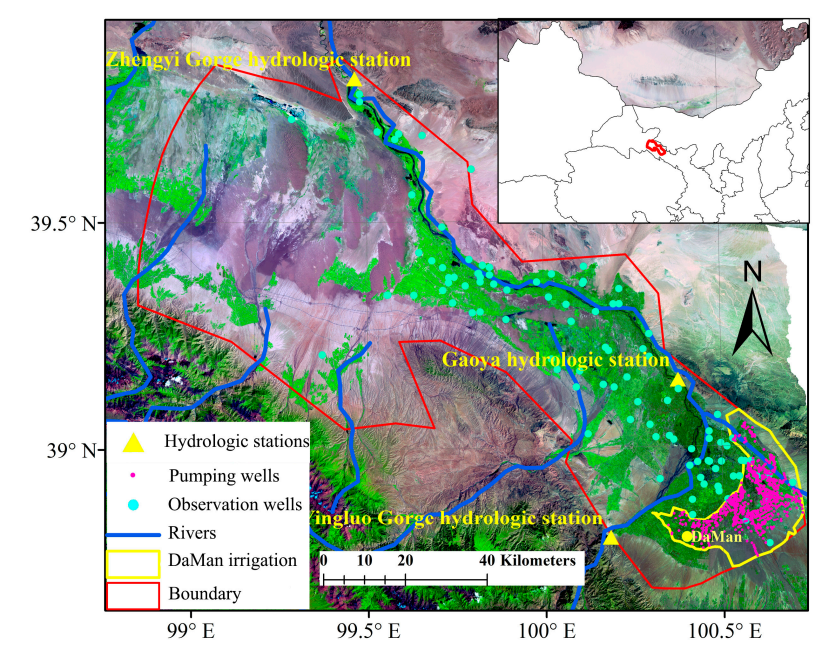

Figure 1. Location and map of the middle reaches of the Heihe River Basin and the Daman irrigation district.

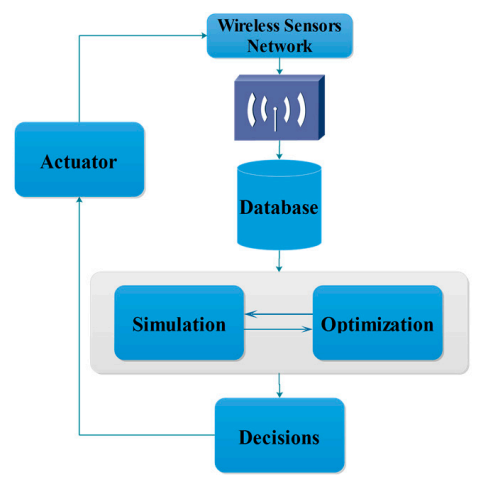

Figure 2. Scheme of the real-time groundwater management system. 


\subsection{Simplex Method}

The groundwater management problem was formulated by three components: an objective function, a set of decision variables, and constraints. The optimization problem is defined as maximizing or minimizing the objective function, which is usually stated in terms of decision variables subject to the specified constraints. In this study, the optimization problem was to identify the maximum groundwater pumping rates (decision variables) in the Daman irrigation district (objective function) subject to a specified groundwater level (constraints) at the Daman borehole. In other words, the objective function was to maximize:

$$
\begin{array}{ll} 
& Z=C^{\mathrm{T}} X \\
\text { Subject to, } & A X \leq B \\
& L B \leq X \leq U B
\end{array}
$$

where $Z$ was the pumping yields in the Daman irrigation district; $C^{T}=\left(c_{1}, c_{2}, \ldots, c_{n}\right)^{T}$ represented the weights of the decision variables, which were all set to 1 in this study; the superscript $T$ stands for vector transpose; $X$ was the pumping rates; $A$ represented the vector of response coefficients, which were calculated from the response matrix method in the following section; $B=(b 1, b 2, \ldots, b p)^{\mathrm{T}}$ was the vector of groundwater level constrains; $L B$ and $U B$ were the lower bound and upper bound of the pumping rates, respectively.

\subsection{Response Matrix Method}

Due to the large computational cost of the numerical model, the response matrix method was applied to transform the groundwater management problem into an optimization function approximately. The response matrix method is briefly summarized as follows, and the interested reader can refer to [27] for a detailed description.

The idea of the response matrix is to approximate the relations between the decision variables and the constraints which are originally described in the numerical model by physical equations. Suppose the groundwater level is a function of a set of pumping rates.

$$
H_{i, j, k, t}=H_{i, j, k, t}(Q w)
$$

where $Q w$ represents the vector of all withdrawal and/or injection rates in the Daman irrigation district; $H$ is the groundwater level; $(i, j, k)$ represents a location in the three-dimensional aquifer system; $t$ is time.

A first-order Taylor series expansion can be applied to approximate the groundwater level at the constraint location:

$$
H_{i, j, k, t}(Q w)=H_{i, j, k, t}^{0}\left(Q w^{0}\right)+\sum_{n=1}^{N} \frac{\partial H_{i, j, k, t}}{\partial Q w_{n}}\left(Q w^{0}\right)\left(Q w_{n}-Q w_{n}^{0}\right)
$$

where $H^{0}$ and $Q w^{0}$ represent the base (initial) condition of groundwater level and pumping rates; $\frac{\partial H_{i, j, k, t}}{\partial Q w_{n}}$ are the response coefficients; $n$ is the number of decision variables.

The response coefficients are approximated as

$$
\frac{\partial H_{i, j, k, t}}{\partial Q w_{n}} \approx \frac{\Delta H_{i, j, k, t}}{\Delta Q w_{n}}=\frac{H_{i, j, k, t}\left(Q w_{\Delta n}\right)-H_{i, j, k, t}^{0}\left(Q w^{0}\right)}{\Delta Q w_{n}}
$$

where $\Delta Q w_{n}$ is the perturbation for the $n$-th decision variable; $Q w_{\Delta n}$ represents the pumping rates after perturbation. 


\subsection{Numerical Groundwater Flow Model}

In this study, the response coefficients were calculated from a three-dimensional groundwater model, which was constructed by MODFLOW. For detailed information about MODFLOW, please refer to [28]. Several physical processes were identified as principal processes in the study area (shown in Table 1).

Table 1. Packages used in the establishment of the groundwater model.

\begin{tabular}{cc}
\hline Physical Processes & MODFLOW Packages \\
\hline Irrigation and precipitation & RCH [28] \\
Evapotranspiration & EVT [28] \\
Groundwater exploitation & Well [28] \\
River & STR [29] \\
Boundary influx & Well [28] \\
\hline
\end{tabular}

\subsection{Data Collection}

The management system was conducted from 1986 to 2012 with a yearly stress period due to the availability of data. Landsat TM/ETM+ images in 1986 [30], 2000 [31], and 2007 [32] were processed to obtain the cultivated area. Groundwater levels from 42 monitoring wells (Figure 1), an annual runoff at Yingluo, Gaoya, and Zhengyi hydrologic stations, and irrigation and groundwater exploitation data were used and obtained from the WestDC [33].

\section{Results}

\subsection{Calibration}

The groundwater simulation was conducted from 1986 to 2012 with yearly stress periods. The parameters of the middle reaches of the HRB were calibrated. The calibration of the model was accomplished by a combination procedure of the parameter estimation code PEST [34] and a trial-and-error method. Eight sub-zones of hydraulic conductivities were identified based on the hydrogeological map [35] and adjusted (shown in Figure 3). The observed and simulated groundwater level at all observation wells in the middle reaches of the HRB during the calibration period indicated a reasonable match. The calculated and observed streamflow hydrographs at Gaoya and Zhengyi Gorge hydrologic stations basically had similar trends, with the calculated streamflow being in good agreement with the observed ones over a yearly time step. The calculated groundwater levels and streamflow during the simulation periods can be found in [27].

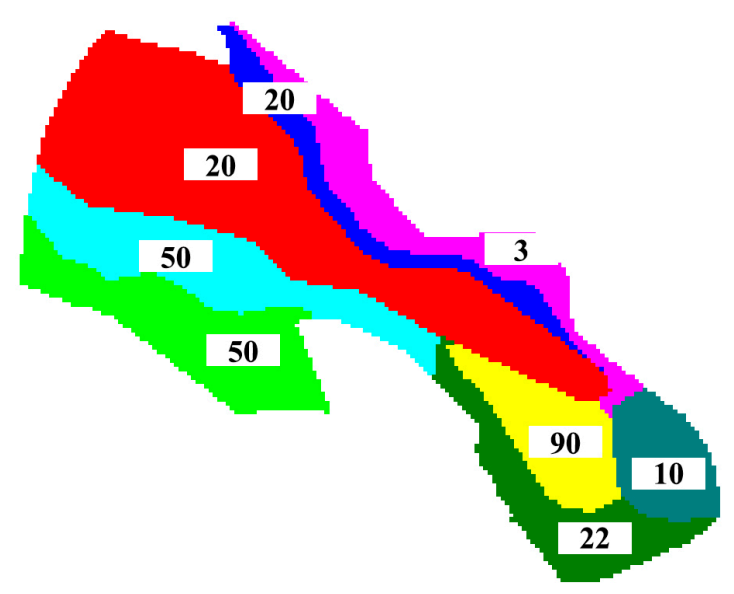

Figure 3. The sub-zones and values of hydraulic conductivities. 
The groundwater pumping data, irrigation data, and the cultivated areas obtained from WestDC [33] were divided into three periods (1986-1989, 1990-2001, and 2002-2012). Therefore, the water balance for the middle reaches of the HRB was analyzed corresponding to the three periods (Figure 4). Figure 4 indicated that the main groundwater recharge source of the study area was the leakage from the Heihe River, which accounted for about $50 \%$ of the total recharge amount. Other important sources of groundwater recharge were the irrigation backflow and the lateral inflow from the mountain area, which accounted for about $27 \%$ and $21 \%$, respectively. The principal sink term of the groundwater was the drainage from the groundwater to the river, which accounted for about $80 \%, 67 \%$, and $60 \%$ of the total amount in different periods. The difference between periods represented the groundwater dynamics, which is mainly due to the different groundwater exploitations in different periods. In addition, the figure also indicates that the groundwater system was under negative water balance for almost 30 years.

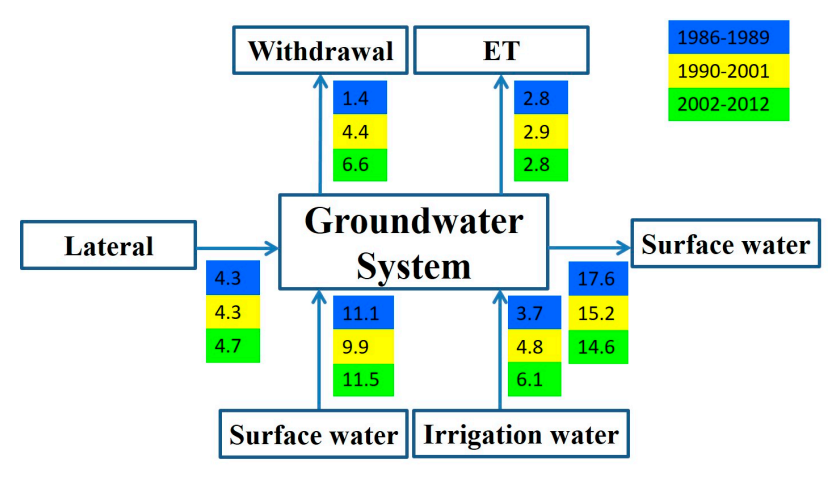

Figure 4. Water balance of the middle reaches of the HRB.

\subsection{Optimization}

The calibration results indicated a serious shortage and decreasing trend of groundwater resources in the study area. Therefore, a test case for groundwater management was conducted and analyzed. In our system, the optimization problem was maximizing the total groundwater pumping yields in the Daman irrigation district subjected to groundwater level constraints at the Daman observation borehole. Several groundwater level constraints of $1474 \mathrm{~m}, 1475 \mathrm{~m}$, and $1476 \mathrm{~m}$ were applied (hereafter referred as $\mathrm{S1}, \mathrm{S} 2$, and $\mathrm{S} 3$, respectively). By analyzing the historical data, the $L B$ and $U B$ of the pumping yields in all scenarios were set to be $0.05 \times 10^{8} \mathrm{~m}^{3} / \mathrm{a}$ and $1.0 \times 10^{8} \mathrm{~m}^{3} /$ a respectively. In most studies, offline data were used to sustainably manage the groundwater resources. However, the groundwater level was observed incessantly. A WSN with HOBO water level Logger U20-001-01 was deployed to measure and record the continuous groundwater level. A real-time system was implemented to manage the groundwater resources by combining incessant real-time observation and optimization. The data from 1986 to 2012 were used to simulate the real-time data by inputting the simulation/optimization model at each time step. At each time step, the groundwater level was calculated by simulating the groundwater system. The decision variables (pumping rates) were used to adjust the simulated groundwater level to the constraints. The optimized groundwater levels are shown in Figure 5 to indicate reasonable control based on the constraints. Pumping yields, which were optimized in three different scenarios with different groundwater level constraints, are shown in Figure 6. The average pumping yields for S1, S2, and S3 were $\sim 0.57 \times 10^{8} \mathrm{~m}^{3} / \mathrm{a}, \sim 0.2 \times 10^{8} \mathrm{~m}^{3} / \mathrm{a}$ and $\sim 0.1 \times 10^{8} \mathrm{~m}^{3} / \mathrm{a}$, respectively. The annual amount of surface water diverted from the Heihe River was around $1.36 \times 10^{8} \mathrm{~m}^{3} / \mathrm{a}$, which was used to sustain a cultivated area of about $3.29 \times 10^{8} \mathrm{~m}^{2}$ according to the data collected by WestDC [33]. We assume that the climate condition remains at an average level with the usual runoff and lateral flow from the upper reaches. Under this assumption, the total cultivated area, which could be supported by the limited water resources in the Daman irrigation district, could be calculated considering the optimal irrigation water demand (on average $~ 570 \mathrm{~mm}$ expressed in water depth) [36]. 
Therefore, the cultivated area, which could be sustained by the available water resources in S1, S2 and S3, were $\sim 3.38 \times 10^{8} \mathrm{~m}^{2}, \sim 2.73 \times 10^{8} \mathrm{~m}^{2}$ and $\sim 2.56 \times 10^{8} \mathrm{~m}^{2}$, respectively. However, according to the current irrigation techniques, the average total irrigation water in the Daman Irrigation district was 601 mm expressed in water depth [36], which meant that $\sim 0.22 \times 10^{8} \mathrm{~m}^{2}, \sim 2.3 \times 10^{8} \mathrm{~m}^{2}$ and $\sim 0.2 \times 10^{8} \mathrm{~m}^{2}$ of the cultivated area could be supported.

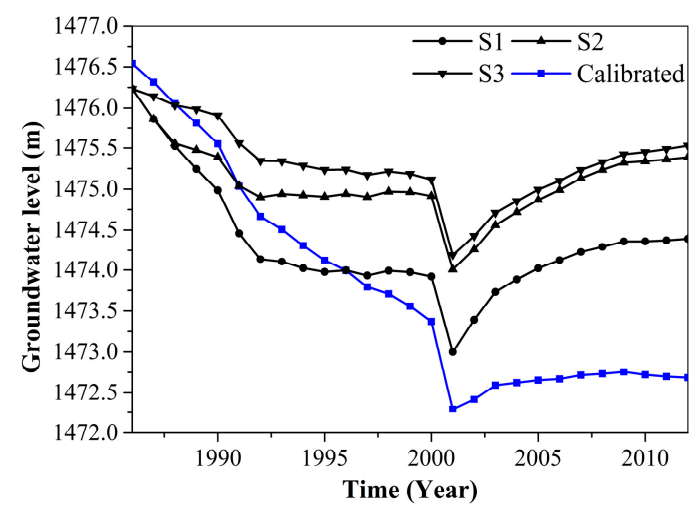

Figure 5. The optimized groundwater levels for S1, S2, and S3 and the base condition (the calibrated groundwater level) at the Daman observation well.

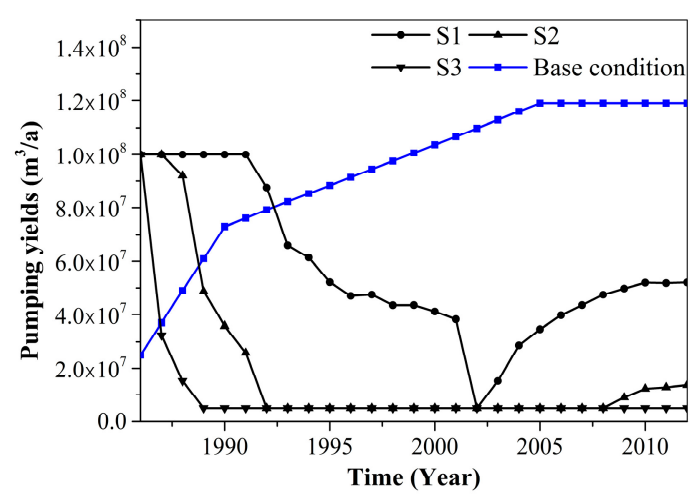

Figure 6. The optimized pumping yields for S1, S2, and S3 and the base condition (the pumping yields from the collected data) of the Daman irrigation district.

\subsection{Real-Time Management of Groundwater Resources}

The real-time management of groundwater resources was accomplished by integrating WSN techniques, a simulation process, and optimization modeling. The simulation process was prepared before the optimization and real-time management using offline data to calibrate and verify. The real-time data from WSN were used to optimize the groundwater level by adjusting the pumping rates. The management system was updated when new groundwater level observations and pumping data became available. The decision-makers could manage the groundwater resources based on the real-time optimization and make better decisions. Furthermore, the real-time management system was integrated into a web-based platform (shown in Figure 7), which helped the decision-makers. The platform emphasized the study area and the location of the borehole. By clicking the (yellow) label for the borehole, detailed information was displayed. The observed groundwater level (dashed line in Figure 7) was plotted based on the in-situ observation stored in the database, which was measured and transferred by the WSN. The groundwater resource was optimized based on different groundwater level constraints and is displayed in the chart (solid line in Figure 7). The optimized curves presented the results of the decision based on groundwater level constraints. The observed groundwater level 
was an indicator of the management effects. Therefore, the decision-makers could make decisions at every time step based on the real-time observations and optimizations.

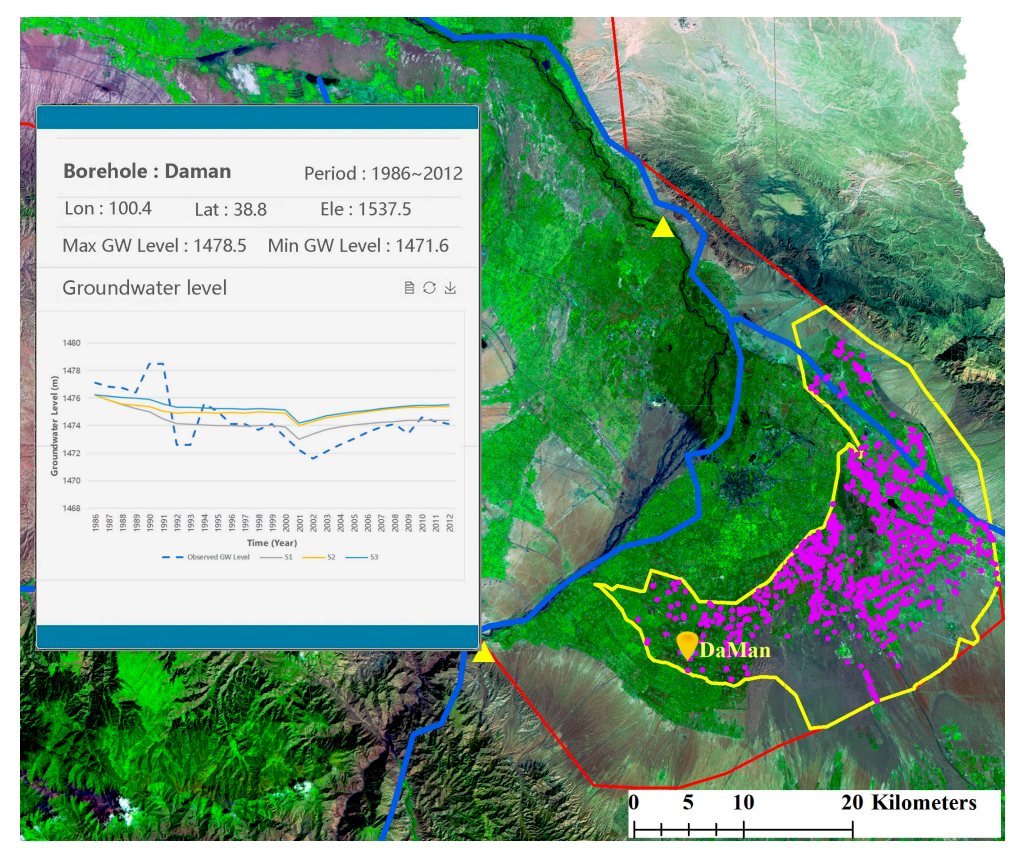

Figure 7. Real-time monitoring and management of groundwater resources.

\section{Conclusions}

In this study, a real-time management system of groundwater resource was designed and developed based on WSN techniques. This system was preliminarily deployed in the middle reaches of the Heihe River Basin (HRB) to help solve the groundwater depletion problem. Daman irrigation in the middle reaches of the HRB was selected as the pilot region. The management system contained a correlated simulation-optimization model, which offered the optimal decision variables subject to constraints. With the facility of WSN techniques, a real-time management system was implemented to provide accurate decision support. Reasonable results were obtained by appropriately defining the initial/boundary conditions and calibrating the parameters. The simulated results revealed that Daman irrigation district have experienced a dramatic groundwater level drawdown of $20 \mathrm{~m}$ over the past three decades. The optimization employed in this simplex method was proved to be effective, controlling the groundwater level from drawdown. Under normal conditions, the cultivated area for different scenarios, which could be sustained by the available water resources, was calculated. Furthermore, the real-time management system was integrated into a web-based platform to ease decision-makers' work. In the future, we will deploy more wireless sensors and further expand the concept of real-time management to the entire basin considering the surface water to regulate water resources on a basin scale.

Acknowledgments: The authors would like to thank the associated editors and the reviewers for their precious time and efforts in reviewing our paper and providing constructive comments to improve the paper. Gratitude is expressed to the Cold and Arid Regions Science Data Center at Lanzhou (http:/ / westdc. westgis.ac.cn) for providing data. This work was supported by the National Natural Science Foundation of China under Grant No. 61402210 and 60973137, the Program for New Century Excellent Talents in University under Grant No. NCET-12-0250, the Major Project of High Resolution Earth Observation System with Grant No. 30-Y20A34-9010-15/17, the "Strategic Priority Research Program" of the Chinese Academy of Sciences with Grant No. XDA03030100, the Fundamental Research Funds for the Central Universities under Grant No. lzujbky-2016-140, the Gansu Telecom Cuiying Research Fund under Grant No. lzudxcy-2013-4, Google Research Awards, and the Google Faculty Award, China. This work was also facilitated by the help of University of Wollongong's University Internationalisation Committee's UIC Linkage program and the Global Challenge Program's Travel Fund. 
Author Contributions: Qingguo Zhou and Chong Chen initialized the research idea and developed the models. Huaming Chen, Gaofeng Zhang, and Rui Zhou collected the data. Yingnan Yan helped with implementation and tested the entire system. The manuscript was written by Chong Chen and Huaming Chen, and Jun Shen provided reviews and comments. All authors were engaged in the final manuscript preparation and agreed to its publication.

Conflicts of Interest: The authors declare no conflict of interest.

\section{References}

1. Nations, U. World Population Prospects, the 2017 Revision. Available online: http://www.un.org/en/ development/desa/population/ (accessed on 12 January 2018).

2. Mulligan, K.B.; Brown, C.; Yang, Y.C.E.; Ahlfeld, D.P. Assessing groundwater policy with coupled economic-groundwater hydrologic modeling. Water Resour. Res. 2014, 50, 2257-2275. [CrossRef]

3. Ma, Y.H.; Fan, S.Y.; Zhou, L.H.; Dong, Z.H.; Zhang, K.C.; Feng, J.M. The temporal change of driving factors during the course of land desertification in arid region of north China: The case of Minqin County. Environ. Geol. 2007, 51, 999-1008. [CrossRef]

4. Huo, A.-D.; Dang, J.; Song, J.-X.; Chen, X.H.; Mao, H.-R. Simulation modeling for water governance in basins based on surface water and groundwater. Agric. Water Manag. 2016, 174, 22-29. [CrossRef]

5. Shen, Q.; Gao, G.Y.; Hu, W.; Fu, B.J. Spatial-temporal variability of soil water content in a cropland -shelterbelt-desert site in an arid inland river basin of northwest China. J. Hydrol. 2016, 540, 873-885. [CrossRef]

6. Reca, J.; Roldán, J.; Alcaide, M.; López, R.; Camacho, E. Optimisation model for water allocation in deficit irrigation systems: I. Description of the model. Agric. Water Manag. 2001, 48, 103-116. [CrossRef]

7. Li, X.; Ma, M.; Wang, J.; Liu, Q.; Che, T.; Hu, Z.; Xiao, Q.; Liu, Q.; Su, P.; Chu, R.; et al. Simultaneous remote sensing and ground-based experiment in the Heihe river basin: Scientific objectives and experiment design. Adv. Earth Sci. 2008, 23, 897-914.

8. Michael, H.A.; Voss, C.I. Evaluation of the sustainability of deep groundwater as an arsenic-safe resource in the Bengal basin. Proc. Natl. Acad. Sci. USA 2008, 105, 8531-8536. [CrossRef] [PubMed]

9. Budge, T.J.; Sharp, J.M. Modeling the usefulness of spatial correlation analysis on karst systems. Groundwater 2009, 47, 427-437. [CrossRef]

10. Cloete, N.A.; Malekian, R.; Nair, L. Design of smart sensors for real-time water quality monitoring. IEEE Access 2016, 4, 3975-3990. [CrossRef]

11. Zhou, X.-L.; Huang, K.-Y.; Wang, J.-H. Numerical simulation of groundwater flow and land deformation due to groundwater pumping in cross-anisotropic layered aquifer system. J. Hydro-Environ. Res. 2017, 14, 19-33. [CrossRef]

12. Rupérez-Moreno, C.; Senent-Aparicio, J.; Martinez-Vicente, D.; García-Aróstegui, J.L.; Calvo-Rubio, F.C.; Pérez-Sánchez, J. Sustainability of irrigated agriculture with overexploited aquifers: The case of Segura basin (SE, Spain). Agric. Water Manag. 2017, 182, 67-76. [CrossRef]

13. Reca, J.; Roldán, J.; Alcaide, M.; Lopez, R.; Camacho, E. Optimisation model for water allocation in deficit irrigation systems: II. Application to the Bémbezar irrigation system. Agric. Water Manag. 2001, 48, 117-132. [CrossRef]

14. Li, Y.; Huang, G.; Nie, S.; Chen, X. A robust modeling approach for regional water management under multiple uncertainties. Agric. Water Manag. 2011, 98, 1577-1588. [CrossRef]

15. Singh, A. Groundwater modeling for the assessment of water management alternatives. J. Hydrol. 2013, 481, 220-229. [CrossRef]

16. Singh, A. Managing the environmental problem of seawater intrusion in coastal aquifers through simulation-optimization modeling. Ecol. Indic. 2015, 48, 498-504. [CrossRef]

17. Sadeghi-Tabas, S.; Samadi, S.Z.; Akbarpour, A.; Pourreza-Bilondi, M. Sustainable groundwater modeling using single- and multi-objective optimization algorithms. J. Hydroinform. 2017, 19, 97-114. [CrossRef]

18. Wu, B.; Zheng, Y.; Wu, X.; Tian, Y.; Han, F.; Liu, J.; Zheng, C. Optimizing water resources management in large river basins with integrated surface water-groundwater modeling: A surrogate-based approach. Water Resour. Res. 2015, 51, 2153-2173. [CrossRef]

19. Safavi, H.R.; Falsafioun, M. Conjunctive use of surface water and groundwater resources under deficit irrigation. J. Irrig. Drain. Eng. 2017, 143, 05016012. [CrossRef] 
20. Rundel, P.W.; Graham, E.A.; Allen, M.F.; Fisher, J.C.; Harmon, T.C. Environmental sensor networks in ecological research. New Phytol. 2009, 182, 589-607. [CrossRef] [PubMed]

21. Lin, B.; Huangfu, Y.; Lima, N.; Jobson, B.; Kirk, M.; O’Keeffe, P.; Pressley, S.; Walden, V.; Lamb, B.; Cook, D. Analyzing the relationship between human behavior and indoor air quality. J. Sens. Actuator Netw. 2017, 6, 13. [CrossRef]

22. Jiang, P.; Xia, H.; He, Z.; Wang, Z. Design of a water environment monitoring system based on wireless sensor networks. Sensors 2009, 9, 6411-6434. [CrossRef] [PubMed]

23. Barnhart, K.; Urteaga, I.; Han, Q.; Jayasumana, A.; Illangasekare, T. On integrating groundwater transport models with wireless sensor networks. Ground Water 2010, 48, 771-780. [CrossRef] [PubMed]

24. Genxu, W.; Jian, Z.; Kubota, J.; Jianping, S. Evaluation of groundwater dynamic regime with groundwater depth evaluation indexes. Water Resour. Res. 2008, 80, 547-560. [CrossRef]

25. Rui, J.; Xin, L.; Baoping, Y.; Wanming, L.; Xiuhong, L.; Jianwen, G.; Mingguo, M.; Jian, K.; Yanlin, Z. Introduction of eco-hydrological wireless sensor network in the Heihe river basin. Adv. Earth Sci. 2012, 27, 993-1005.

26. Wu Adan, G.J.; Wang, L. Improvement and application of automatic data in Heihe river basin downloading system. Remote Sens. Technol. Appl. 2015, 30, 1027-1032.

27. Chen, C.; Shen, J.; Zhang, G.; Zhao, R.; Liu, J.; Zhou, Q. A Groundwater management tool for solving the pumping yields minimization problem: A case study in the Heihe river basin. In Proceedings of the 4th International Conference on Advanced Cloud and Big Data (CBD 2016), Chengdu, China, 13-16 August 2016; Institute of Electrical and Electronics Engineers Inc.: Chengdu, China, 2016; pp. 289-295.

28. Harbaugh, A.W. Modflow-2005. The US Geological Survey Modular Ground-Water Model-the Ground-Water Flow Process; U.S. Geological Survey, Tech. Methods: Reston, VA, USA, 2005.

29. Prudic, D.E. Documentation of a Computer Program to Simulate Stream-Aquifer Relations Using a Modular, Finite-Difference, Ground-Water Flow Model; USGS Open-File Report 88-729; USGS: Reston, VA, USA, 1989; Volume 113.

30. Wang, Y.; Yan, C.; Wang, J. Landuse/Landcover Data of the Heihe River Basin in 1986; Heihe Plan Science Data Center: Lanzhou, China, 2011.

31. Wang, Y.; Yan, C.; Wang, J. Landuse/Landcover Data of the Heihe River Basin in 2000; Heihe Plan Science Data Center: Lanzhou, China, 2011.

32. Wang, J.; Hu, X. Landuse/Landcover Data of Zhangye City in 2007; Heihe Plan Science Data Center: Lanzhou, China, 2011.

33. Northwest Institute of Eco-Environment and Resources, C. Westdc. Available online: http:/ / westdc.westgis.ac.cn/ (accessed on 12 January 2018).

34. Doherty, J.E. Pest: Model-Independent Parameter Estimation-User Manual; Watermark Computing: Corinda, Australia, 2012.

35. Wang, J.; Zhao, J.; Wang, X.; Feng, B. Ecological and hydrological map for the Heihe river basin: Data management center for the Heihe Plan. 2013. Available online: http:/ / westdc.westgis.ac.cn/data/ 96eb358d-d112-46ac-9118-3cf5e016f33d (accessed on 12 January 2018).

36. Wu, X.; Zhou, J.; Wang, H.; Li, Y.; Zhong, B. Evaluation of irrigation water use efficiency using remote sensing in the middle reach of the Heihe river, in the semi-arid Northwestern China. Hydrol. Process. 2014, 29, 2243-2257. [CrossRef]

(C) 2018 by the authors. Licensee MDPI, Basel, Switzerland. This article is an open access article distributed under the terms and conditions of the Creative Commons Attribution (CC BY) license (http:/ / creativecommons.org/licenses/by/4.0/). 